\title{
LOS INFORMES DE LA CENSURA SOBRE LAS TRES PRIMERAS NOVELAS DE JOSÉ JIMÉNEZ LOZANO
}

\author{
GUADALUPE ARBONA ABASCAL \\ Universidad Complutense de Madrid
}

\begin{abstract}
Resumen
En el trabajo se analizan las arbitrariedades de la censura durante el franquismo y se señala cómo las obras de José Jiménez Lozano constituyen un desafío a los mismos presupuestos censores: sus historias muestran las consecuencias de usar la autoridad como freno a la libertad, así como la irreductibilidad de una conciencia libre. Se hace a partir de una colección de cartas inéditas sobre la escritura del autor de 1960. En ellas se descubre la confusión de las advertencias que, a instancias de la autoridad eclesial, realiza la autoridad política sobre sus artículos. En segundo lugar, se analizan los expedientes de la censura sobre las tres primeras novelas del escritor: Historia de un otoño (1971), El sambenito (1972) y La salamandra (1973), los tres conservados en el Archivo General de la Administración. La censura conmina a mantener una imagen de España con fe y pensamiento únicos.

Palabras clave: censura, franquismo, Jiménez Lozano, Historia de un otoño, El sambenito, La salamandra.
\end{abstract}

\section{CENSORSHIP FILES REGARDING THE THREE FIRST NOVELS OF JOSÉ JIMÉNEZ LOZANO}

\begin{abstract}
Absract
The present study analyses the arbitrariness of censorship during Franco's regime. It is pointed out how the works of José Jiménez Lozano are a challenge to the censorship principles: the stories show the consequences of using authority as a deterrent of freedom, as well as, the irreducibility of a free conscience. It is based on the unpublished letters regarding José Jiménez Lozano's writings on 1960. In them appears the muddled warnings issued by the political authority, following the advice of the ecclesial authority, against his articles. Secondly, the present work studies the censorship files regarding the
\end{abstract}


three first novels of the writer: Historia de un otoño (1971), El sambenito (1972) y La salamandra (1973), which are kept at Archivo General de la Administración. The censorship authority urges to maintain Spain's image of a country of one faith and one thought.

Keywords: censorship, francoism, Jiménez Lozano, Historia de un otoño, El sambenito, La salamandra.

\section{INTRODUCCIÓN}

Con fecha del 10 de mayo de 1960, el escritor y periodista José Jiménez Lozano ${ }^{1}$ recibía una amonestación de la delegación del Ministerio de Información y Turismo en Valladolid ${ }^{2}$. La advertencia se realizaba a través de una misiva que no iba dirigida al escritor directamente, sino a Miguel Delibes Setién, director de El Norte de Castilla. En 1960 Delibes era director del periódico decano de la prensa española y Jiménez Lozano escribía como colaborador ${ }^{3}$. Las relaciones entre Delibes y Jiménez Lozano desde 1956 eran de una estrecha colaboración profesional y personal $^{4}$. La carta había sido motivada por las quejas que el delegado recogía

${ }^{1}$ La página oficial del autor (en línea: <http://www.jimenezlozano.com> [consulta: 25 de junio de 2019]) consigna y clasifica las obras, ofrece una cronología, una semblanza biográfica, inéditos, noticias y una bibliografía de y sobre el autor actualizada diariamente.

${ }^{2}$ Las tres cartas que citaremos a lo largo del artículo están custodiadas en el archivo del autor, en su biblioteca de Alcazarén (Valladolid). Se han podido leer y se conserva copia.

${ }^{3}$ Pasará a ser redactor del diario en 1965; subdirector en 1978 y director desde 1992 hasta su jubilación, en 1995.

${ }^{4}$ En el epílogo a Un cristiano en rebeldía, Miguel Delibes pone de manifiesto la relación con el escritor y el trabajo profesional compartido: "Y Pepe se va; marcha siempre con su ancha sonrisa y sus prisas porque el coche de línea no aguarda. Y en sus prisas olvida inevitablemente en la redacción la gorra, o un libro, o la cartera [...] Con Pepe Lozano, Carlos Campoy, Martín Descalzo, Miguel Ángel Pastor, Bernardo Arrizabalaga, César Alonso y Manuel A. Leguineche, fundé un día una sección de El Norte titulada «El caballo de Troya». Esto de «El caballo de Troya» es una cabeza de puente en el mundo de la frivolidad, dedicada a enseñar a pensar a los que ordinariamente no piensan y tratar de ordenar el pensamiento de los que de buena fe desean pensar. La sección cayó muy bien; la sección llevaba el espíritu de Pepe Lozano que es, para entendernos, un espíritu de caridad justa (justa es una palabra incómoda, pero insustituible, en este caso, para delimitar el concepto caridad, tan maltratado el pobre). Un espíritu, en suma, que está, afortunadamente, cada día más extendido por el país» (Jiménez Lozano, 1963: 179-180). Es sabido además que la novela de Delibes, Cinco horas con Mario (1966), está dedicada al escritor amigo. 
de don Modesto Herrero, vicario de la archidiócesis de Valladolid, y recaían sobre el contenido de los artículos de Jiménez Lozano porque no se sometían a la ortodoxia («se vierten opiniones poco ortodoxas e incluso arbitrarias en materias tan delicadas como las que advierte»). Se refiere a los artículos de Jiménez Lozano en esa primera época de colaboración con El Norte de Castilla y concretamente al titulado «Las ollas podridas $»^{5}$ en el que, según carta anterior, fechada el 5 de mayo de 1960, el vicario se dirigía al Delegado Provincial del Ministerio de Información y Turismo para decirle que el escritor hace «críticas históricas inexactas, que pueden suponer ataques contra la Iglesia», dice que realiza «interpretaciones inexactas de la actualidad católica» y acusa a Jiménez Lozano de ser un "librepensador calificado», cosa que parece considerarse negativamente. Las tres acusaciones dan por supuesto que el poder civil y el eclesiástico tienen una serie de referencias compartidas, en las que, por ejemplo, no cabe ser «librepensador». El final de la carta habla por sí mismo de esa connivencia que se establece entre los representantes autorizados de dos instituciones: "Sin ánimo de denuncia, pero con deseo de que esto se corrija, le propongo a $\mathrm{Vd}$. para que tenga la intervención que estime más oportuna». El delegado del Gobierno, Antolín Santiago de Juárez, no tardaba en hacer suya la 'sugerencia' del vicario y le pedía a Delibes: "Mucho te agradezco que adviertas al firmante»; y añadía «espero que tomes las medidas oportunas con el fin de que no se repitan en lo sucesivo estos hechos, que pueden causar evidente daño en materias para todos tan sagradas y dignas de obligado respeto, cuales son las que atañen a la Iglesia y a la actualidad católica». En la misiva se ve que la autoridad civil no se refiere a un ordenamiento jurídico objetivo sino a un ordenamiento moral que presume compartido, es decir, que el Estado debe defender a la Iglesia ${ }^{6}$.

${ }^{5}$ Merino Bobillo (2009) clasifica gran parte de los centenares y centenares de artículos publicados por el escritor. Hasta el momento es la obra de conjunto más completa sobre sus colaboraciones en prensa.

${ }^{6}$ En aquel momento estaba vigente todavía la ley de prensa de 1938, aprobada por Ramón Serrano Suñer, que obligaba a someter las publicaciones a censura previa, censura que pasará a ser voluntaria con la Ley de Prensa y de Imprenta de 1966, la llamada ley Fraga que, como señala Abellán (1980: 78), no supuso una apertura, sino que castigó a los editores que se vieron obligados a censurar a sus autores. 
El episodio pone de manifiesto un modo de coartar la libertad de conciencia. De hecho, Jiménez Lozano, como se puede comprobar en los primeros artículos y ensayos, está pensando y cavilando sobre estas cuestiones ${ }^{7}$. Y en ellos se ve que no acepta la alianza de poder entre la Iglesia y el Estado para menoscabo de la libertad intelectual, artística y religiosa. La emergencia que el escritor siente respecto a esta cuestión es la preocupación que atraviesa sus estudios y telón de fondo de novelas y relatos. Por poner solamente dos ejemplos de su narrativa en el arco de una trayectoria muy fecunda, la libertad frente al poder es una tensión permanente que alimenta los argumentos de sus obras. Lo está ya en su primera novela Historia de un otoño (1971), en la que se narra la historia de un gesto de libertad, frente al poder religioso y eclesiástico; y lo está en una de las últimas, Retorno de un cruzado (2013), en la que cuenta la vida de un médico dolorido porque ha sufrido en sus carnes la España rota durante la sangrienta Guerra Civil del 36, que se enfrentó en los términos de una nueva cruzada ${ }^{8}$. Podemos hablar, por tanto, de más de sesenta años de escritura, reflexiva y creativa, en la que se visitan diferentes periodos de la historia de España en los que se conculcan libertades o, al menos, se ven seriamente forzadas ${ }^{9}$.

Esta tesis sobre la singularidad de la cultura y la religiosidad españolas en términos de confrontación hallan un punto de arranque en el pensamiento de Américo Castro, autor con el que el escritor dialogó y a quien

\footnotetext{
${ }^{7}$ En esos años y los inmediatamente siguientes, el escritor publica varios ensayos desarrollando estas ideas. Más adelante, se comentan los artículos que salen en los diarios del momento y sus recopilaciones posteriores. El lector interesado en el desarrollo de los extremos que se comentan los puede encontrar en: Nosotros los judíos (1961), Un cristiano en rebeldía (1963), Meditación española sobre la libertad religiosa (1966), El ateísmo (1969), Juan XXIII (1973), Los cementerios civiles y la heterodoxia española (1978).

${ }^{8}$ Para entender el sentido de la novela y el drama del personaje que ha tenido que vivir en los dos bandos que dividieron España es muy útil considerar el juicio histórico de la guerra civil que aparece en otras ficciones del autor y que se recoge en el ensayo «E la Guerra Civile divenne una Crociata» (Jiménez Lozano, 1987).

${ }^{9}$ Haciendo cómputo desde sus primeras colaboraciones en El Norte de Castilla en 1956 y llegando hasta el presente. Hasta el día de su muerte, el 9 de marzo de 2020, el escritor seguía plenamente lúcido y activo y, de hecho, había anunciado la publicación de un nuevo ensayo sobre la precariedad de la libertad hoy que se titularía: «Algunos incordios sobre la libertad civil, y una coda sobre las prohibiciones necesarias», comunicación a través de correo electrónico del 19 de marzo de 2019.
} 
encuentra referente de su pensamiento. A partir de Castro, Jiménez Lozano estudia la pervivencia en nuestra historia de periodos oscuros en los que la Iglesia llega a dar forma o incluso a identificarse con el Estado:

Entre nosotros, no es que la Iglesia aniquile la realidad del Estado o el Estado se sacralice como con Carlomagno, no es que el derecho natural quede subsumido en categorías canónicas, es que es el Estado el que, en sí, es religioso, sacral; y no existe derecho natural o civil alguno. Es la Iglesia la que se ha hecho Estado, como la fe se ha hecho carne y sangre, biología y casta (Jiménez Lozano, 1971b: 213).

Se sacraliza la forma de control para liquidar las diferencias y se fragua una complicidad entre la Iglesia y el Estado nociva para la convivencia. La consecuencia inmediata es que la libertad se hace heroica para los que no son cristianos; y se liquida para aquellos 'católicos' que la asumen como imperativo, pero sin someterla a una comprobación personal, es decir, queda reducida a la defensa de una moral o doctrina y se abandona la vivencia existencial ${ }^{10}$.

Volvemos al episodio iniciado de 1960. Se puede suponer, a partir de los documentos que hemos estudiado, que el escritor, precisamente para romper esa alianza, decide dirigirse directamente al vicario; con ese gesto desactiva la sucesión jerárquica en la que se había producido la comunicación (vicario-delegado-director) y aborda el problema como laico de a pie y escritor cristiano que, libremente, escribe a un vicario de la Iglesia, tal y como se puede colegir de la carta que el periodista recibe del Arzobispado de Valladolid. No hemos localizado la carta del escritor, pero sí la respuesta del Vicario que nos da muchas claves. Está fechada el 1 de agosto de 1960 y en ella don Modesto Herrero que, como se ha dicho, amenazaba al escritor, le recuerda en la misiva que firma, ahora sí, de puño y letra y sin intermediarios, que «puede hacer mucho bien por la facilidad y soltura de su pluma» y añade que «la Iglesia necesita siempre y más ahora de la contribución de los buenos hijos para cumplir su misión en la tierra». El tono, como se ve, es entre formal y condescendiente, no así el gesto de

${ }^{10}$ Con este pensamiento, el escritor se adelanta al espíritu del Concilio Vaticano II, especialmente a las perspectivas que se desarrollan en el documento sobre la libertad religiosa (Dignitatis Humanae) que fueron difíciles de entender, al menos inicialmente, por gran parte de la Iglesia española. En este contexto se sitúa la respuesta a la carta que citaba más arriba. 
Jiménez Lozano que había hecho por romper rigideces y mediaciones. A la recomendación, se añade la obligación que siente el vicario de cumplir una «misión de freno»; es decir, sigue afirmando que su función es censurar y controlar el pensamiento de un cristiano. Por último, pide disculpas porque ha intentado "mezclar lo político y lo religioso", cosa que, desde luego y como es evidente, ha hecho. Y le deja una puerta abierta para una conversación: «tendré gran placer en hablar largamente y cambiar impresiones sobre aquellos puntos que le preocupan» e insiste en la despedida: «Me ofrezco incondicionalmente para cuanto pueda ayudarle y serle útil». Posteriormente, la relación que empezó de un modo abrupto fue ganando cordialidad y llegó a interlocución con el arzobispo Goldaraz ${ }^{11}$ :

recuerdo solamente que, tras mi visita a don Modesto Herrero, vicario general, y luego al arzobispo Goldaraz, quedé amiguísimo, una vez acreditado que mi idea de la libertad nada que tenía que ver con el liberalismo, aunque sí mucho el periódico donde yo trabajaba. Volví varias veces y don Modesto, me documentó algunas cuestiones de la Historia de la Iglesia española en el XX [...] Y el arzobispo Goldaraz, cuando me encontré con él en Roma durante el Concilio me dijo bromeando que, como ya sabría yo, el Concilio iba a tratar de la libertad religiosa, pero que, como él y yo ya nos habíamos puesto de acuerdo en esa cuestión, ya me podía yo volver a Alcazarén, y él se quedaba esperando a ver lo que decían sobre el asunto los obispos». Y añade con un tono irónico: «En gran parte esta era la Iglesia española y 'reaccionaria'» (correo electrónico del 19 de marzo de 2019).

Episodios como este son frecuentes en la trayectoria de Jiménez Lozano, cosa que hace posible ver que el tono y los modos de la censura permitían, al menos en estos casos, dar comienzo a una relación más libre. Al mismo tiempo, hay que decir que se repetirán desde sus inicios como colaborador de El Norte de Castilla en 1956 y serán frecuentes a partir de 1964, cuando inicia su andadura con Destino y publica en la sección titulada «Cartas de un cristiano impaciente». Por otro lado, no se restringirán a los años finales del franquismo, ni a la transición ni siquiera a los primeros años de la democracia, van más allá de esas fechas

${ }^{11}$ José García Goldaraz, arzobispo de Valladolid de 1953 a 1973, participó en el Concilio Vaticano. 
con episodios que no concuerdan con una sociedad libre. A lo largo de esta trayectoria periodística, dilatada en el tiempo, la nota dominante de sus escritos ha sido la defensa de la libertad. No creo que se ajuste a una evolución en los términos de adscripción ideológica o política que apunta Gregorio Morán (2014: 574) cuando dice: «la trayectoria intelectual de Jiménez Lozano, narrador notable y agudo analista periodístico, va del catolicismo liberal de esa primera época, que años después se desplazará al conservadurismo». Con El País colabora desde 1976 y en 1986 declinará los encargos por custodiar la libertad; lo mismo que dejará de escribir en el $A B C$-fue firma de las Terceras de 1993 a 2006- por el mismo motivo, es decir, preservar su libertad y significativamente la religiosa ${ }^{12}$.

Ahora bien, este episodio temprano -Jiménez Lozano todavía no ha publicado ningún libro- es muy significativo por la respuesta del escritor a ciertas amonestaciones. Lo cierto es que no se arredra, tal y como se puede comprobar si se leen los artículos publicados en Destino, durante la década de los años $60^{13}$ y hasta 1984.

\section{LOS INFORMES DE LA CENSURA}

Si las cartas que citábamos servían para ponernos en el contexto temprano de las primeras publicaciones de Jiménez Lozano y los recelos que

\footnotetext{
${ }^{12}$ Son episodios aún pendientes de estudio. Estudios básicos para abordar esta perspectiva son Merino Bobillo (2009), Álvarez de Toledo (2010), Arbona Abascal (2013), Higuero (1983 y 1988) e Ibáñez Ibáñez (2005). Además, pueden fundamentarse en los cinco volúmenes de artículos seleccionados con los que contamos. Un cristiano en rebeldía (1963) recoge la columna de José Luis Martín Descalzo en El Norte de Castilla, con prólogo de José Luis Martín Descalzo y epílogo de Miguel Delibes; La ronquera de Fray Luis y otras inquisiciones (1973) recoge los artículos publicados en Destino en la sección «Cartas de un cristiano impaciente», con prólogo de José Luis Aranguren; Retratos y soledades, (1977) con prólogo de Laín Entralgo; Ni venta ni alquilaje (2002) contiene artículos periodísticos procedentes de los diarios El Norte de Castilla, El País y $A B C$ y de las revistas Destino y El Semanal entre los años 1968 y 1999; Buscando un amo y otras aprensiones (2017) reúne artículos de $A B C$, La Razón y el grupo PROMECAL.

${ }^{13}$ Baste señalar algunos de los títulos de los artículos para colegir que aborda temas espinosos y desde luego 'censurables' del año 1964: «Un concordato expiatorio» (Destino, $\mathrm{n}^{\circ}$ 1409, 8 de agosto), «Pidiendo una Inquisición» (Destino, $\mathrm{n}^{\circ}$ 1411, 22 de agosto), "¿La Virgen es de derechas?» (Destino, $\mathrm{n}^{\circ}$ 1415, 19 de septiembre) o "Del anatema al diálogo» (Destino, $\mathrm{n}^{\circ} 1418,10$ de octubre).
} 
suscitaron, lo que haremos a continuación es analizar una serie documentos preservados en el Archivo General de la Administración (Alcalá de Henares, Madrid). Estos recogen los informes de las primeras obras impresas de Jiménez Lozano. Hay un total de diez expedientes, de los cuales cuatro se refieren a obras de ficción y seis a ensayos, dos de ellos recopilaciones de textos breves, ya que recogen artículos publicados en la prensa y en revistas ${ }^{14}$. Dado el interés de los documentos referidos a las tres primeras novelas, me detendré algo más en ellos y se dejan los restantes para futuras investigaciones.

La censura administrativa desde sus formas mismas muestra la confesionalidad del Estado, es decir, el poder del Estado defiende la moral cristiana y la Iglesia se apoya en el Estado. El esquema inquisitivo de los expedientes la pone de manifiesto con las preguntas que formula: « ¿Ataca el Dogma? ¿A la moral? ¿A la Iglesia o a sus Ministros? ¿Al Régimen y sus instituciones?». Además, a través de los informes se percibe que las prácticas se extendían, sin criterios claros, pero con la pretensión de que la trasmisión de un bien cultural debía ser controlada. Es lo que intenta poner de manifiesto Andrés de Blas (1999) invitando a hacer estudios multidisciplinares del fenómeno. Antes Cisquella, Erviti y Sorolla (1977) estudiaron la importancia de entrevistar a los editores y entrar en sus archivos para recomponer otro de los sujetos que era víctima de la presión censora. También el estudio de Neuschafer (1994) analiza en obras de esos años las formas y estrategias textuales que utilizan los autores para evitar la censura, creando un nuevo discurso. A nosotros nos interesa seguir la pista -y este estudio es un comienzo- de esa operante alianza entre censura moral y estatal que el escritor abulense enraíza en una cuestión histórica: la manera de entender lo religioso como control

\footnotetext{
${ }^{14}$ Los ensayos con documentación en el Archivo General de la Administración son Meditación española sobre la libertad religiosa (1966) con un expediente fechado en 1965 (es decir es el único texto anterior a la ley de Prensa de 1966; dado que tengo abierta una investigación sobre este expediente con el profesor Santiago López-Ríos remito a la futura publicación sobre este tema); El ateísmo (1969) con expediente del mismo año; La ronquera de fray Luis y otras inquisiciones (1973) con expediente de 1973; (1973) con expediente de 1974; Retratos y soledades (1977), expediente de 1977 y Los cementerios civiles y la heterodoxia española (1978), expediente de 1978. A los ensayos se añade el expediente a El santo de mayo (1976), una colección de cuentos con expediente de 1976. Es reseñable que no exista ningún expediente sobre la colección de ensayos titulada $U n$ cristiano en rebeldía (1963).
} 
o freno sobre posibles desvíos y no como pensamiento libre. Este conflicto, que no podemos abordar de manera exhaustiva en estas páginas, hace que el poder se conciba a sí mismo con un valor sacral.

Empezamos por los informes que se refieren a las tres primeras novelas que aportan noticias interesantes sobre el modo de actuar de la censura y ponen de manifiesto la confusión respecto a los contenidos sobre los que informaba, además se verán las contradicciones halladas entre los informes de los diversos censores que lo hacían sobre una misma obra $^{15}$. Los tres expedientes que analizaremos se refieren a obras publicadas con posterioridad a la llamada 'ley Fraga' (Ley 14/1966, de 18 de marzo, de Prensa e Imprenta $)^{16}$, que no obligaba a la censura previa, y alentaba a una consulta llamada 'voluntaria'. Como es bien sabido, había una serie de limitaciones que el editor o director del libro, revista o periódico tenía que tener en cuenta para no arriesgarse a que la publicación fuese retirada. Abellán (1980: 209) cree que esta ley «acentuó el carácter coercitivo de la censura», porque "aunque trató de dar cuerpo legal al pluralismo interno del régimen» (1980: 116), cree que esta modalidad censora obligaba a los editores a vigilar y a expurgar porque si se consideraba que "lo publicado había infringido de algún modo la ley, el editor era subsidiariamente cómplice del delito» (1980: 118). Además, y en esto coincide con Andrés de Blas (1999: 290), se producen procesos de autocensura. Teniendo en cuenta este ambiente de control y las consecuencias que implicaba: consejos y recomendaciones de los editores, elección temerosa de los argumentos, corrección del lenguaje, ausencia de temas religiosos, evitación de dilemas morales, etc., destaca la osadía del escritor de ponerlos en el centro de sus obras. A este ejercicio libre, habría que añadir que la torpeza y la arbitrariedad de los informes tienen resquicios para su activación, como se verá a continuación.

\footnotetext{
${ }^{15}$ Los documentos aparecen clasificados bajo los números (03), que clasifica cultura, y 50, que se refiere a la censura editorial. Agradezco a Evelia Vega González, Jefa de Referencias del AGA, y a su equipo la amabilidad y profesionalidad con la que hizo posible la localización de los documentos.

16 Véase BOE, $\mathrm{n}^{\circ}$ 67, 19 de marzo de 1966, págs. 3310-3315 (disponible en: <https://www.boe.es/eli/es/l/1966/03/18/14> [consulta: 28 de marzo de 2019]).
} 


\section{EL EXPEDIENTE DE CENSURA SOBRE HISTORIA DE UN OTOÑO}

El expediente que se refiere a la primera novela de José Jiménez Lozano, Historia de un otoño, es el más escueto ${ }^{17}$. Publicada en Destino dos años antes, es una novela que no planteó problemas a los censores. Aun así, Jiménez Lozano asumía un riesgo sobre el que ya sabemos estaba advertido, y publica una novela cuyo tema principal es la libertad. Trata sobre los últimos días de la abadía femenina de Port-Royal, mandada arrasar por Luis XIV, con el consentimiento de la Iglesia, bajo la acusación de seguir las doctrinas de Jansenio. La historia relata la resistencia de las que se negaron a firmar algo que desconocían, es decir, si las proposiciones condenadas de San Agustín estaban o no en el libro de Jansenio, las monjas no sabían latín, ni teología, ni habían leído a Jansenio, por eso, la firmeza de su negativa no se interpreta -en la historia- como una oposición religiosa, sino resultado de un uso adecuado de la razón. A pesar de ello se las condenó. La novela entra de lleno en la tragedia que supone el intento de coartar la libertad de unas monjas que solo obedecían a su conciencia. Es decir, la historia, en cierta medida y de manera implícita, daba en la línea de flotación de los presupuestos que mantenían vivo un sistema de censura en el franquismo y además ponía ante los lectores las consecuencias existenciales de cualquier gobierno o estado que reprima la libertad de conciencia. Así comenta el autor el sentido de la novela:

Las monjas supusieron la primera actuación de una conciencia meramente civil antes de la famosa modernidad, porque se negaron a firmar lo que se las pedía, no por razones religiosas, sino por razonamiento. Ellas no habían leído ni a San Agustín ni a Jansenius y no podían afirmar ni negar las relaciones entre la teología de estos. Aquí está su grandeza. Dijeron que ellas podían obedecer al Papa, a los obispos y al Rey, pero no decir lo que no sabían. Se las quitó de en medio [...] Mi jansenismo está en la identificación con esa conciencia civil, sin andar amparándola en teologías [...] porque el Estado no tiene que ver nada con las conciencias, un territorio que no

${ }^{17}$ El expediente de la novela es el número 1849; tiene como fecha de entrada el 20 de febrero de 1971 y resolución de 23 de febrero de1971. 
debe pisar 'ni canciller ni nadie' [...] que eso le hacía 'más peligroso que seis ejércitos' (Arbona Abascal, 2008: 74 n. 2).

Este peculiar 'jansenismo' del autor -si es que así se puede llamar por su conciencia civil libre- es la que pone en aprietos a la censura y al sistema. El censor que informa sobre la novela es Eusebio Ceballos Piñas, en el expediente del Archivo General de la Administración. Ceballos acepta la novela y solamente advierte que hay ciertos párrafos en las páginas $(77,108,146$ y 160) donde se narran luchas jansenistas y jesuíticas problemáticas, pero añade que están enunciados "en un plano general», por lo que el texto se acepta. El censor no vio problemas en la novela, probablemente -esa es nuestra hipótesis- porque el episodio se situaba fuera de nuestras fronteras, es decir, no atacaba el nacional catolicismo hispánico; además, porque no se comprendió el horizonte universal que alcanzaba, ciertamente desde una historia particular, pero que entraba de lleno a criticar una represión de la libertad. A este respecto, conviene traer las menciones del autor cuando manifiesta su perplejidad por la resonancia que sí tuvo el texto en la antigua Checoslovaquia y, más en concreto, como fue signo de la libertad y libro de referencia entre las gentes de la «Carta 77»: «Es una historia de una vez ¿no? Aunque ya sé que el que se me ocurriera contarla en España no se le ocurre ni al que asó la manteca. Pero en la Checoslovaquia de la «Carta 77» fue un éxito inimaginable, y hasta los camaradas premiaron al traductor» (Arbona Abascal, 2008: 74 n. 2). La difusión de la obra fue posible por la traducción de Josef Forbelsky, que obtuvo el premio a la misma en 1977; el mismo traductor cuenta la historia del texto en el contexto del movimiento de protesta de los intelectuales checos que exigían a la república socialista libertad y respeto a los derechos fundamentales (Forbelsky, 1983 y 2003). La obra fue señera en la petición de libertades europeas y, sin embargo, no se sintió la pertinencia de la historia por debajo de los Pirineos. O no se quiso ver. Desde luego exigía una agudeza intelectual y comparativa mayor. 


\section{EL EXPEDIENTE DE CENSURA SOBRE EL SAMBENITO}

La segunda novela de Jiménez Lozano se publica en 1972. Se titula El sambenito y relata el proceso de la Inquisición a Pablo de Olavide. La narración relata el juicio inquisitorial al ilustrado, amigo de Voltaire y Diderot y último procesado de la Inquisición en 1778. El episodio se narra desde el dolor del encausado y sus familiares y también desde las perplejidades, dudas y cobardías de los últimos inquisidores. Muestra esta recreación del juicio contra Olavide el último esfuerzo inquisitorial para hacer un alegato y demostrar su fuerza y así apagar lo que se pensaba que eran 'veleidades' liberales.

El expediente que se refiere a este texto es el número $6077^{18}$. Incluye un informe lector completamente opuesto al del dictamen. Mientras el segundo es elogioso y alaba el acierto de describir las luces y las sombras de la Inquisición española en sus contradicciones más hirientes, el primero, firmado por Pedro Rodrigo Martínez, es muy negativo y observa que la obra no debe admitirse. La pregunta que nos hacemos es por qué llegó a pesar más el dictamen que el informe lector. Y en el expediente no hallamos documentos que nos orienten. Es cierto que como dice Abellán (1980: 87-88) la censura actuaba sin un corpus de criterios objetivado, aunque reconoce que había dos áreas de prohibiciones: «la intocabilidad del sistema implantado por el franquismo» y la moral pública que derivaban del «integrismo católico». Desde luego los criterios eran de lo más confuso, como también fruto de las contradicciones de lecturas poco lúcidas y miedos al sistema. De hecho, el mismo autor censurado, aborreciendo un sistema así, dice que los censores «no tenían muchas entendederas, y lo que tenían era miedo» (correo electrónico del 19 de marzo de 2019). No es que este comentario justifique el ejercicio censor, pero sí explica sus contradicciones.

Vayamos por partes. En primer lugar, el informe lector hace una nota negativa en toda regla. Acusa al escritor de pintar «un sañudo retrato de la España y su Iglesia en el siglo XVIII» y tacha la obra de un conjunto en el que se esgrimen todos «los tópicos y manidos argumentos de la Leyenda Negra española, ahora reverdecida». Se trata pues de un primer

${ }^{18}$ Tiene fecha de entrada del 18 de mayo de 1972 y fecha de salida del 20 de mayo de 1972. 
juicio general que se refiere a la imagen que devuelve de España. En segundo lugar, se refiere a la técnica narrativa utilizada. Alaba la habilidad porque «todo parece narrado por otras personas». Ciertamente, esta novela se basa en el encaje narrativo en el que el uso de cartas y documentos de los informes de la Inquisición dan la forma al relato y verosimilitud al conjunto. Este juego de diferentes puntos de vista, narrativamente conjugados, quiere poner en el centro el drama y el horror de la condena a muerte de un hombre. Sin embargo, Rodrigo Martínez insinúa que la estrategia narrativa es una maniobra para eludir la censura. Tan es así, que la condena del texto se hace en términos muy duros: «La obra, sectaria y tendenciosa, aprovecha el hecho histórico de Pablo de Olavide para verter grandes peroratas de fuerte tufillo liberaloide, progresista y neo-voltaireanismo, con aseveraciones que aun dentro de la ficción novelesca revisten especial gravedad». Es decir, el contenido filosófico e ideológico convierte el texto en soporte de propaganda y no repara en señalar que un pensamiento liberal, progresista y neo-volteriano es dañino. Añade una crítica al lenguaje que define como «aspectos de forma delicados y audaces [...], amén de otros totalmente recusables [...] en los que las descripciones procaces con mezcla de irreverencia e incluso blasfemia». Con estas últimas valoraciones de la prosa, llegamos a este elemento repetitivo y constante que ofrecen los informes de censura y es esa identificación entre retrato de una España negra y ataque a la Iglesia. Dice así: «En el fondo es un ataque a la Iglesia tradicional, a la que identifica plenamente con la Inquisición, y a la España Histórica». El informe está firmado el 18 de mayo de 1972.

Y solo un día después, el 19 de mayo de ese mismo año, en otro documento adjunto aparece el otro informe en unos términos completamente diferentes. El dictamen, tal y como aparece al final, es el siguiente: «Lo considero plenamente AUTORIZABLE». Este segundo reporte, elogioso con la novela y certero en la interpretación, insiste, en el carácter aleccionador y salva la obra precisamente por su carácter cristiano. La suma de los dos, es decir, un informe negativo y otro positivo, parece determinar una solución intermedia, la de silencio. Más allá del dictamen final, se puede llegar a la conclusión de que, aun siendo informes de naturaleza diferente -el primero condena, el segundo salva- asombra confirmar que los dos se sienten empujados a hacer un juicio moral sobre la novela. Es como si el principio gnoseológico de los censores estuviese movido por 
el control de la moralidad de los textos. De nuevo nos encontramos con criterios arbitrarios y no sujetos a legislación civil que, según el modo de ver de Jiménez Lozano, están en las entrañas de la confusión española. Si el sentimiento español coincide con una definición de la identidad, se deja poco espacio a la naturaleza libre del cristianismo que genuinamente está en el origen de los textos del escritor, es decir, la afirmación de la persona, cuyo valor no puede estar en peligro por su creencia y pensamiento, más aún las diferencias de pensamiento y de creencia son las que enriquecen una sociedad.

\section{EL EXPEDIENTE DE CENSURA SOBRE LA SALAMANDRA}

Analizaremos en tercer lugar el expediente que se refiere a La salamandra. La novela se publicó por primera vez en 1973 en la editorial Destino. Es un relato sobre la Guerra Civil española que cuenta la contienda desde la voz de las víctimas. La perspectiva del relato es la de un personaje humilde, Damián Sotero. Se trata de un anciano que, recluido en una residencia, saca sus recuerdos ante la presencia de un viejo conocido. En su discurso, agitado y doliente, cuenta su infancia en un pueblo de Castilla, pasa revista a su formación juvenil en el anarquismo madrileño, se lamenta de sus violentas acciones en la guerra y por fin, al terminar la contienda, narra su experiencia como camarero en un café de Madrid. El relato es una larga y sentida perorata que, con un eficaz lenguaje conversacional, recuerda y cuenta crímenes y bestialidades cometidos por odio hacia los «otros» en nombre de la salvaguarda de una creencia o una ideología. El expediente de la novela es el número $641^{19}$. Como en los casos anteriores, la obra se sometió a la censura después de ser publicada, cosa que corrobora el que se halle un ejemplar de la novela en el expediente; aparece con páginas dobladas, subrayados y párrafos resaltados que advierten de aquellos contenidos censurables. Además del libro, los documentos que reúne el expediente son tres. Un primer informe firmado por el lector Martos que describe la novela así:

Especie de memorias de un viejo anarquista recluido en un asilo. En un monólogo que dura todo el libro, el anarquista vomita las peores

${ }^{19}$ Tiene como fecha de entrada el 17 de enero de 1974 y de resolución el 24 de enero de 1974. 
aberraciones sobre los curas, las monjas, la religión, Cristo, etc., etc. El libro es un constante ataque al clero, a la religión y a veces francamente blasfemo.

Los subrayados del ejemplar son señales de Martos y, leídos de manera exenta, podrían parecer un ataque a la Iglesia. Sin embargo, esta lectura es parcial si se tiene en cuenta que el sentido de la novela reside en la denuncia dolorida de la violencia desatada y confrontación clerical que supuso la guerra civil. Es decir, Martos no llegó a comprender la intención del relato. Más bien parece que le mueve el miedo y por eso, en su informe, habla del 'dilema' en el que se encuentra el informador. Dice así:

El dilema que plantea ${ }^{20}$ es el siguiente. Dadas las actuales relaciones entre la Iglesia y el Estado en España, saber o decidir si es misión de esta Ordenación Editorial resolverle problemas a la Iglesia, como el de la publicación de este libro, o dejar que ella se los resuelva sola. En el primer caso, el libro lo consideramos DENUNCIABLE aunque convendría quizá fuera revisado por un asesor religioso. En el segundo caso, se podría aplicar el SILENCIO ADMINISTRATIVO.

El lector Martos tiene dudas que ponen de manifiesto cómo había actuado la censura hasta ahora, es decir, los poderes públicos cuidaban de que no se publicasen ataques a la Iglesia y presume que en esta obra los hay. Ahora bien, percibe cierta distinción entre lo que debe 'defender' la Iglesia, porque se piensa erróneamente que sus principios eran o debían ser los de todos, y lo que es misión del Estado. Por eso duda. Martos deja la cuestión abierta, aunque sigue pensando que la Iglesia debe 'defender' algo. Es precisamente aquí donde entroncamos con el siguiente informe. Está firmado por Ángel Aparicio un día antes y su veredicto es de ACEPTADO, por tanto, bien diferente al informe dubitativo de Martos. Las razones que da es que «No hay objeción alguna para su contenido». La descripción que hace de la novela es más escueta:

Damián, anciano huésped de un asilo, rememora con un antiguo amigo y correligionario su pasado, deteniéndose especialmente en los años de nuestra guerra de liberación. Miliciano anarquista cuenta con un estilo desgarrado los sucesos vividos por él como espectador o protagonista a

${ }^{20}$ Omito una coma que aparece entre sujeto y verbo y que es, evidentemente, un error. 
través de un monólogo casi ininterrumpido. Al final, pone tanto calor en despertar la conciencia dormida de los españoles, para que sepan enfrentarse con la Verdad, que el esfuerzo le produce la muerte.

Si este segundo informe es mucho más acertado -aunque guarda la corrección política de llamar a la Guerra Civil «guerra de liberación»-, cabe decir que la línea de la Dirección de la Cultura Popular sigue siendo ambigua, en cuanto asume que los errores que pretende erradicar son, principalmente, los errores contra el dogma, la moral y los ataques a la Iglesia y sus ministros. El informe de Martos venía a completar lo que el de Aparicio no especificaba. Más aún si tenemos en cuenta que el expediente añade un tercer documento: se trata de una «Nota para el Excmo. Sr. Ministro", firmada por Ricardo de la Cierva, Director General de Cultura Popular, fechada el 22 de enero de 1974, que parece dirimir el conflicto planteado por Martos y sobre el que informa al Ministro. Coincide con Martos en que en el libro «se manifiestan opiniones y anécdotas no precisamente ortodoxas respecto a monjas y sacerdotes y otros aspectos de la religión». Es decir, de la Cierva asume la lectura de Martos de que se trata de una novela que ataca a las monjas y curas, etc., pero, decide recomendar el silencio, no sin antes informar al Ministro, de que no cree que puedan derivarse problemas con el poder judicial porque «no hay ánimo alguna de ofensa a nuestra legislación fundamental» y porque esta decisión coincide con la del «asesor el Fiscal del Orden Público».

La novela siguió en circulación gracias al silencio administrativo. A la vista de los informes se pueden concluir varias cosas. En primer lugar, que la censura mezclaba, con una confusión ajena a un Estado verdaderamente laico, las cuestiones políticas y religiosas, ya que utilizaba la censura como instrumento para la defensa de la moral y el dogma. En segundo lugar, que no se entendió la novela de Jiménez Lozano: el relato pone a los lectores delante del lamento -que a ratos llega a ser grito- de las víctimas de la violencia de la Guerra Civil. En tercer lugar, se pone de manifiesto cómo la alianza entre Iglesia y el poder censor no hace más que distorsionar la naturaleza del cristianismo y la misión de la Iglesia, es decir, vivir de la gracia de un crucificado. Esto es, por otro lado, el 'quid' en el que descansa el sentido de la novela de Jiménez Lozano, cuyo título alusivo a un bicho repugnante, una salamandra, hace referencia a un cristo pisoteado que, en su condición de despreciado, es respuesta al grito dolorido del protagonista. 


\section{CONCLUSIONES}

Tras la lectura de los expedientes de censura de las tres primeras novelas del escritor y premio Cervantes, José Jiménez Lozano, podríamos concluir diciendo que las dinámicas descubiertas en los informes parten de una legislación injusta que trataba de limitar la libertad de pensamiento y de creación artística.

Además, se atribuye valor moral para salvaguardar la ortodoxia y la moral cristianas. La utilización de los principios y valores morales como argumentos para autorizar el poder censor del Estado menoscaba la autoridad moral de las dos instituciones -Iglesia y Estado-, haciéndolas cómplices de connivencia en la coacción de la libertad. Esta ambigüedad hunde sus raíces en la historia conflictiva de España. Se ve la confusión de los censores que, ya fuese por el miedo al poder represor o por incapacidad para distinguir entre Iglesia y Estado, propia de un Estado confesional, manifiestan perplejidades y juicios contradictorios respecto a un mismo texto.

Los informes muestran incompetencia literaria para comprender el significado de las obras, cuyos argumentos descansan en personajes que encarnan la libertad de pensamiento y la vivencia de la fe; asimismo dubitaciones en el juicio crítico respecto a las obras y torpezas que permitían soslayar las prohibiciones. El escritor -haciendo uso libérrimo de su mundo literario- se decanta por situaciones, historias y personajes que constituyen un reclamo a una mayor libertad o, según el caso, un lamento por las ocasiones perdidas de su ejercicio. De este modo, las obras ponen en un brete a los censores que, aun mostrando ciertas intenciones aperturistas hacia una distinción entre los fines de la Iglesia y los del Estado, se contradicen.

Volviendo la mirada hacia las cartas conminatorias que se citaban al inicio y a la luz de los expedientes examinados, resulta llamativa la audacia de un escritor que, sabiendo del poder de la censura, no quiso dejar de denunciar a quienes castigasen por ideas y formas de pensar y así seguirá haciendo a lo largo de su trayectoria. De tal modo que hace suyas las palabras de un clérigo del siglo XV, orgulloso de sus conocimientos en derecho (aprendido en la universidad y que, coloquialmente, llama 'bolonias'). El sacerdote afirmaba que nadie puede condenar a otro por 
pensar. De estos hombres desciende la libertad de Jiménez Lozano ante la censura franquista, hombres y mujeres que ha hecho habitar y revivir en sus obras literarias:

...y la verdad es que en la Historia de la Iglesia Antigua y Moderna ha habido cientos de casos de defensa de la libertad por parte de los fieles, antes y después de Juana de Arco. 'iQué yo me sé bien mis bolonias, y el pensamiento no delinque!', decía un cura de una aldea de Soria del siglo XV, cuando le hablaron de la Inquisición (correo electrónico del 19 de marzo de 2019).

\section{BIBLIOGRAFÍA CITADA}

ABELLÁN, M.L. (1980): Censura y creación literaria en España (1939-1976). Barcelona, Península.

Álvarez DE Toledo, B. (2010): «La voz subversiva y crítica de un escritor en la posmodernidad. Los artículos de José Jiménez Lozano en $A B C$ ». En Martínez Díaz, A.N. y Navío Castellano, E. (eds.): Literaturas de la (pos)modernidad. Madrid, Fragua, págs. 149-161.

ANDRÉS DE BLAS, J. (1999): «El libro y la censura durante el franquismo: un estado de la cuestión y otras consideraciones». Espacio, tiempo y forma. Serie V, Historia Contemporánea, 12, págs. 281-301.

ARbona Abascal, G. (2008): El acontecimiento como categoría del cuento contemporáneo. Las historias de José Jiménez Lozano. Madrid, Arco Libros.

- (2013): "La obra periodística de José Jiménez Lozano: la crítica de libros en El País (1976-1986)». En Ubach, A. (ed.): Tejedora de palabras. La lengua y la literatura en relación con los medios de comunicación social. Madrid, Fragua, págs. 21-31.

Cisquella, G., ERviti, J.L. y Sorolla, J.A. (1977): Diez años de represión cultural. La censura de libros durante la Ley de Prensa (1966-1976). Barcelona, Anagrama.

ForBelSKY, J. (1983): «Al margen de una traducción». Anthropos, 25, págs. 7071.

— (2003): «La novela y su circunstancia». En González, J.R.: José Jiménez Lozano. Nuestros Premios Cervantes. Valladolid, Universidad de ValladolidJunta de Castilla y León, págs. 123-128. 
Higuero, F.J. (1983): «La problemática de la libertad en Retratos y soledades de Jiménez Lozano». Anthropos, 25, págs. 71-74.

— (1988): «El jansenismo de Jiménez Lozano», El Ciervo, 453, págs. 41-42.

IBÁÑEZ IBÁÑEZ, J.R. (2005): La escritura reivindicada. Claves interpretativas en los ensayos de José Jiménez Lozano. Valladolid, Conserjería de Cultura y Turismo.

JimÉneZ LozANo, J. (1963): Un cristiano en rebeldía. Salamanca, Sígueme.

- (1971a): Historia de un otoño. Barcelona, Destino.

- (1971b): «El aporte del profesor Américo Castro a la interpretación del sentimiento religioso español». En Laín Entralgo, P.: Estudios sobre la obra de Américo Castro. Madrid, Taurus, págs. 211-245.

- (1972): El sambenito. Barcelona, Destino.

- (1973): La salamandra. Barcelona, Destino.

- (1987) «E la Guerra Civile divenne una Crociata». Storia-Dossier, Ottobre, págs. 19-22.

Merino BobILlo, M. (2009): La Trayectoria intelectual de José Jiménez Lozano a través de su obra en prensa. Tesis Doctoral, Universidad de Valladolid (disponible en: <http://uvadoc.uva.es/handle/10324/131> [consulta: 25 de junio de 2019]).

Morán, G. (2014): El cura y los mandarines. Historia no oficial del Bosque de los Letrados. Cultura y política en España 1962-1996. Madrid, Akal.

Neuschafer, H. J. (1994): Adiós a la España eterna: La dialéctica de la censura. Novela, teatro y cine bajo el franquismo. Barcelona, Anthropos.

Guadalupe ARBONA ABASCAL Universidad Complutense de Madrid arbona@ucm.es 0000-0002-6391-4016 
